Research Article

www.jestr.org

\title{
Cadmium Removal From Aqueous Solution by Capacitive Deionization with Nano- Porous Carbon Electrodes
}

\author{
D.I. Marmanis ${ }^{1, *}$, K.I. Dermentzis ${ }^{1}$, A.K. Christoforidis ${ }^{1}$ and K.G. Ouzounis ${ }^{2}$ \\ ${ }^{\text {I}}$ Department of Petroleum and Natural Gas Technology, Laboratory of Environment Protection, Kavala Institute of Technology, 65404 \\ Agios Loucas, Kavala, Greece, \\ ${ }^{2}$ Department of Environmental Engineering, Laboratory of Environmental Chemistry, Democritus University of Thrace, 67100 Xanthi, \\ Greece
}

Received 10 June 2013; Accepted 25 August 2013

\begin{abstract}
The aim of present work is to determine the efficiency of capacitive deionization on removal of cadmium ions from an aqueous solution using nano-porous carbon aerogel electrodes. The electrosorption performance is investigated at various applied voltages and solution $\mathrm{pH}$ values. For the optimum conditions of applied voltage $1.2 \mathrm{~V}$ and $\mathrm{pH} 6$, the initial cadmium concentration of $200 \mathrm{mg} / \mathrm{L}$ decreased to $5 \mathrm{mg} / \mathrm{L}$ showing a reduction of $97.5 \%$.
\end{abstract}

Keywords: Cadmium, Deionization, Removal, Nanoporous

\section{Introduction}

Cadmium is a very toxic heavy metal and one of the major metallic pollutants originating from agricultural, mining and industrial activities. Various treatment processes such as adsorption, biosorption, ion exchange and electrochemical cadmium from aqueous waste streams. Capacitive deionization or otherwise called electrosorption is an electrochemical ion collection/discharge process which relies on the formation of double-layer supercapacitors at the solution /electrode interface [3-6]. When an electric field is applied between two carbon aerogel electrodes, cations and anions are held in the electric double-layers formed at the cathode and anode surface respectively. The high specific area and electrosorption capacity of the carbon aerogel electrodes enables the efficient electrostatic attraction and removal of ions, resulting in the purification of the treated solution.

\section{Experimental}

The experiments were conducted in a $100 \mathrm{ml}$ plexiglass reactor with dimensions $10 \mathrm{~cm}$ in length, $10 \mathrm{~cm}$ in height and $1 \mathrm{~cm}$ in width. Three electrodes of carbon aerogel were used (Marketech Int. USA) with dimensions $8 \mathrm{~cm}$ in height and $8 \mathrm{~cm}$ in width each one, two anodes and one cathode in the middle. The electrodes were placed vertically in parallel connection to each other at a distance of $0.3 \mathrm{~cm}$ between them. The solution volume was $100 \mathrm{ml}$. The electrodes were

\footnotetext{
* E-mail address: imarm@teikav.edu.gr

ISSN: 1791-2377 @ 2013 Kavala Institute of Technology. All rights reserved.
}

connected to a digital dc power supply (Agilent E3612A, USA) for measuring the electrode potential and current. Conductivity was measured by means of a conductometer (WTW). $\mathrm{pH}$ and temperature were determined using a $\mathrm{pH}$ meter (Hanna). The concentration of cadmium ions was determined by atomic absorption spectroscopy (Perkin Elmer 5100 Atomic Absorption Apparatus PC). All experiments were conducted at room temperature.

\section{Results and Discussion}

\section{Effect of operating parameters}

Effect of $p H$ : The value of $\mathrm{pH}$ is one of the most important parameters controlling both, the physical and electrochemical uptake of cadmium from aqueous solutions. The effect of $\mathrm{pH}$ on removal of cadmium at $1.2 \mathrm{~V}$ bias potential and 40 min residence time, was studied at different solution $\mathrm{pH}$ values adjusted to 2, 4 and 6 and fixed cadmium concentration of $200 \mathrm{mg} / \mathrm{L}$. Experimental results depicted in Fig.1, reveal that the removal of cadmium increases with increasing $\mathrm{pH}$. At more acidic solutions the competition between $\mathrm{H}^{+}$and $\mathrm{Cd}^{2+}$ ions for adsorption on the ionexchangeable sites of the carbon aerogel surface leads to a lower removal of cadmium. The initial cadmium concentration of 200 decreases to 58,37 and $5 \mathrm{mg} / \mathrm{L}$ at the corresponding solution $\mathrm{pH}$ values of 2,4 and 6 , showing a removal percentage of $71,81.5$ and $97.5 \%$ respectively.

Effect of applied voltage: In order to study the effect of applied voltage on cadmium, removal experiments were carried out under varying voltages of $0.4,0.8$ and 1.2 Volt at fixed cadmium concentration of $200 \mathrm{mg} / \mathrm{L}$ and optimum $\mathrm{pH}$ $=6$. The results are shown in Fig.2. Higher removal 
efficiency for cadmium was achieved at higher voltages, as increased voltage increases the flow velocity of electrons and the electrostatic attraction of ions by the opposite charged electrodes.

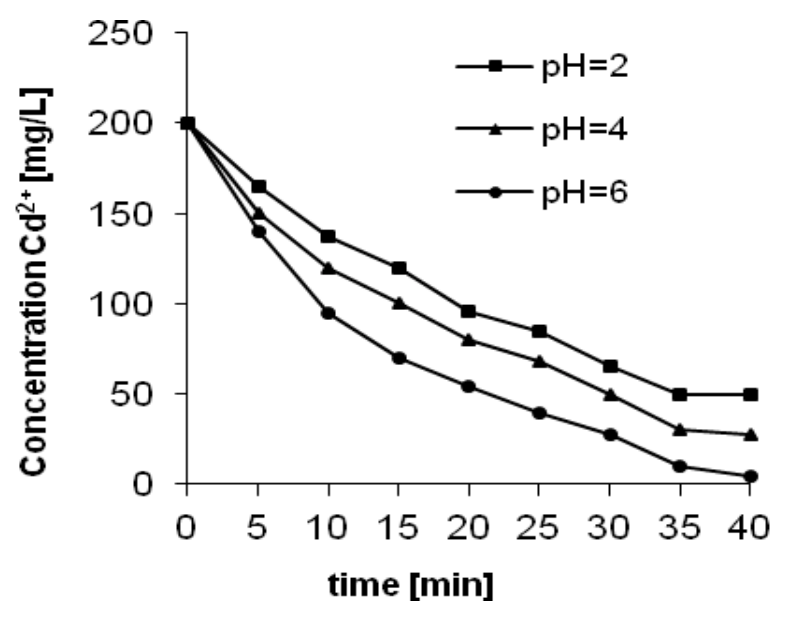

Fig. 1. Concentration variation of cadmium versus time at various solution $\mathrm{pH}$ values

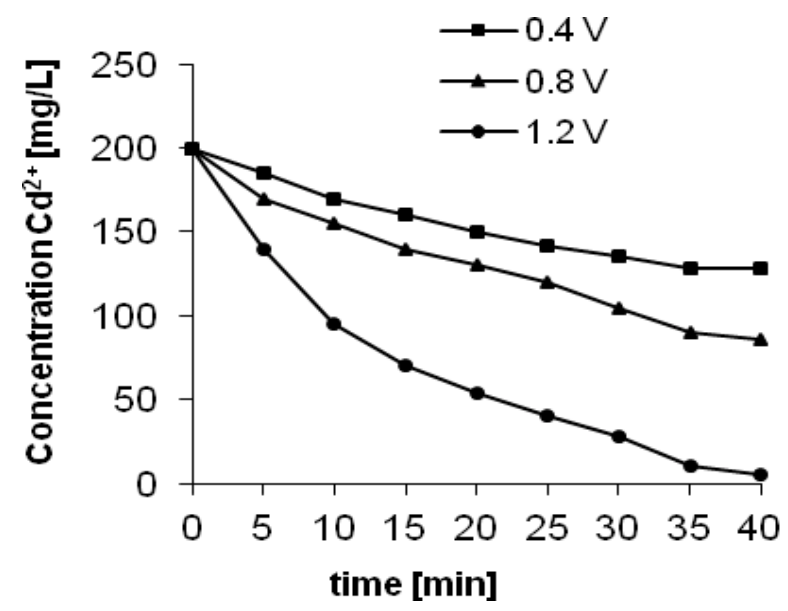

Fig. 2. Concentration variation of cadmium versus time at various applied voltage
The initial concentration of cadmium decreased from 200 to 138,83 and $5 \mathrm{mg} / \mathrm{L}$ at the corresponding applied voltages of $0.4,0.8$ and $1.2 \mathrm{~V}$.

Electrodesorption: The electrosorption process is reversible, as the electrode charge/discharge procedure can be repeated several times without any significant loss of the salt sorption capacity. The electrodesorption step helps to regenerate the electrodes and recover the adsorbed $\mathrm{CdCl}_{2}$ from the electrodes. Regeneration of electrodes can be done in two ways, namely discharging the cell at $0.0 \mathrm{~V}$ or reversing the cell polarity at an opposite charge.

\section{Conclusions}

In this paper, the performance of capacitive deionization for removal of cadmium from dilute aqueous $\mathrm{CdCl}_{2}$ solutions using carbon aerogel electrodes was investigated. Experimental results showed that the electrosorption capacity of cadmium effectively increases with increasing $\mathrm{pH}$ and increasing applied voltage. Electrosorption is a very economic and energy efficient method for water deionization and removal of heavy metals, such as cadmium from wastewater. Further research is needed in order to gain more information about this very promising water deionization technique.

\section{References}

1. K. Dermentzis, A. Christoforidis, D. Papadopoulou, A. Davidis, Environ. Progr. Sust. Energy, 30, 37 (2011).

2. M. Kobya, E. Demirbas, N.U. Parlak, S. Yigit, Environ. Technol. 31, 1471 (2010).

3. I. Cohen, E. Avraham, M. Noked, A. Soffer, D. Aurbach, J. Phys. Chemi., C 115, 19856 (2011).
4. M.A. Anderson, A.L. Cudero, J. Palma, Electrochim. Acta, 55, 3845 (2010).

5. R.L. Clifton, C.A. Rios Perez, R. Naylor, C. Hidrovo, Conf. proc. ASME 2012, 8-12 July 2012, Rio Grande, Puerto Rico.

6. A. Subramani, M. Badruzzaman, J. Oppenheimer, J.G. Jacangelo, Water Res. 45, 1907 (2011). 